\title{
PREPARATION OF ELECTRON PROBE MICROANALYZER STANDARDS USING A RAPID QUENCH METHOD
}

\author{
BY \\ J. I. GOLDSTEIN \\ F. J. MAJESKE \\ H. YAKOWITZ
}

AUGUST 1966

NASA

GODDARD SPACE FLIGHT CENTER

GREENBELT, MARYLAND

GPO PRICE \$

CFSTI PRICE(S) \$

Har sopy (HC)

$2-00$

Microfiche (MF)

50

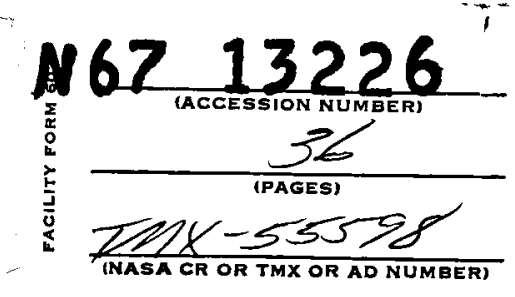




\title{
Preparation of Electron Probe Microanalyzer Standards
}

\author{
Using a Rapid Quench Method
}

by

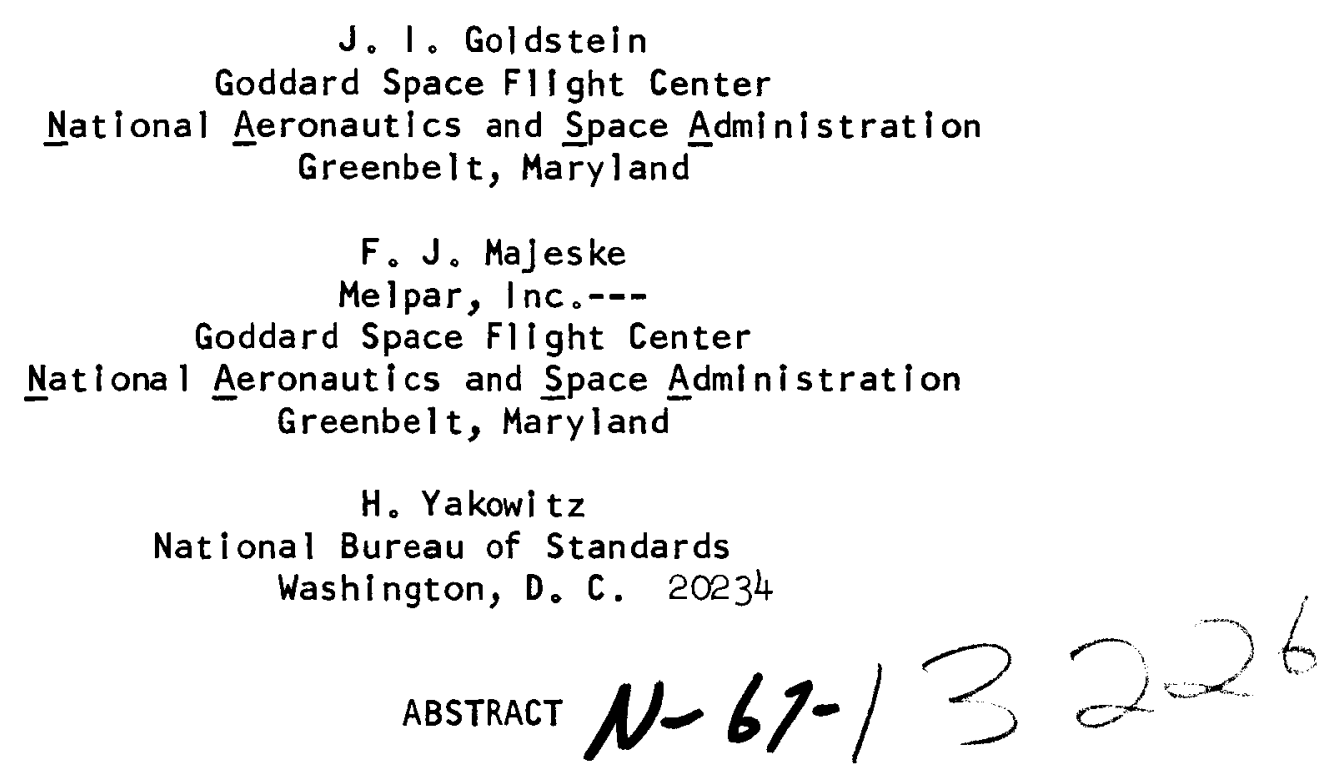

A modified Duwez method of splat cooling In which a small quantlty of molten alloy is accelerated and made to strike a cold substrate having a high thermal conductivity was investigated as a means for preparing several cubic centimeters of standard materials suitable for quantitative electron probe microanalysis. The major requirements for such standards are that the material be homogeneous at micron levels of spatial resolution and that its composition be known. As examples, the Au-Si and Al-Mg binary alloy systems were prepared and characterized by means of electron probe microanalysis, x-ray diffraction, electron microscopy and analytical chemistry. It is concluded that these alloys satisfy all of the requirements for a suitable microprobe standard. The relatively simple and Inexpensive splat cooling device employed is descrlbed in detail. A

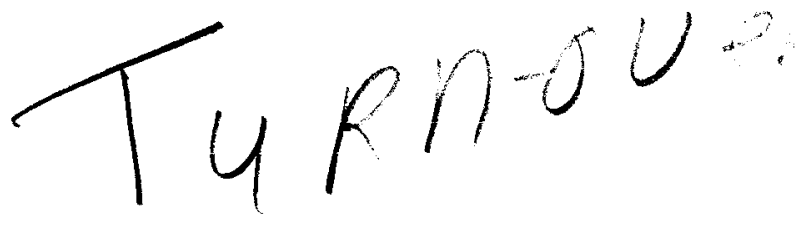


suggested analysis procedure when using splat cooled standards is also outlined. The electron probe microanalyzer results for the Au-Si and Al-Mg systems are evaluated.

KEY WORDS :

Microprobe standards, splat cooling, instrument deslgn, specimen preparation, Au-Si, Al-Mg,quantitative microanalysis.

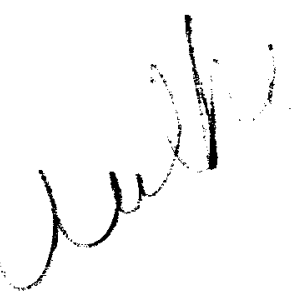


Preparation of Electron Probe Microanalyzer Standards Using a Rapid Quench Method

J. 1. Goldstein

Goddard Space Flight Center

National Aeronautics and Space Administration

Greenbelt, Maryland

F.J. Majeske

Melpar, Inc.---

Goddard Space Flight Center

National Aeronautics and Space Administration

Greenbelt, Maryland

H. Yakowitz

National Bureau of Standards

Washington, D.C. 20234

\section{Introduction}

More than fifteen years ago, Castaing stated that unlike $x$-ray

spectrochemical analysis, quantitative electron probe microanalysis could be accurately performed without intermediate standards. Rather than these, only elemental standards were deemed necessary; a set of correction procedures for the observed relative $x$-ray flux data from unknown and elemental standard was then presented. [1] In the ensuing years the correction models and procedures have been the subject of much research and controversy. The research and controversy continue today--uncertainties in the correction models and in their input parameters have led many workers in the fleld of electron probe microanalysis to the bellef that quantitative analysis can be performed only to one to ten percent of the amount present. The latter figure is appropriate to low concentrations and the former to high concentrations. [ 2 ]

Therefore, when analysls having a maximum error of one percent relative is required, appropriate multicomponent standards are required as well. The requirements for multicomponent standards are twofold, 
namely, that they must be homogeneous on the micron scale and that the compusition must be known accurately. The types of standards required vary with the objectives of the anaiyst. In the earth sciences, for example, multicomponent standards are needed for as many as 12 or more elements. Fortunately, many natural minerals can be used. [3] However, many standards are needed in cases where accurate analysis ( $\pm 1 \%$ rel.) are required for a whole range of compositions, for example, in diffusion analysis. Also, in testing the correction procedures themselves, it is very important to be able to select standards which can be used to evaluate only one of the correction procedures at a time. In this case the analyst must be able to prepare and characterize his own standards.

Unfortunately, very few well characterized standards are available. [4] This mainly stems from the fact that they are difficult and expensive to prepare. Several methods for making standards have been suggested. One method is to melt and chill cast the standards. A difficulty found with this procedure is that most such castings produced exhibit segregation of one or more components. There are only a few alloy systems in which the castings of different compositions can be heat treated in a solid solution range and at a high enough temperature to produce a homogeneous standard.

A few binary systems successfully produced as standards by this technique include $\mathrm{Cu}-\mathrm{Zn}, \mathrm{Fe}-\mathrm{Ni}$ and $\mathrm{Cu}-\mathrm{Au}$. [5] [6] [7]

Corollary to this technique and currently under study is a means to prepare standards by powder metallurgical techniques. Micron sized powders are blended and sintered into billets. These billets are then heavily worked by swaging and/or rolling followed by an anneal. Extrusion followed by a long anneal at the highest practical temperature is the final step. [8] This method shows promise but is complex, expensive, and the time required to prepare a standard is great. 
A second method which has been suggested is to use single crystals of intermetallic or inorganic compounds having no reported range of solubility. However, in reality it has been discovered that such compounds do indeed have too large a solubility range to satisfy the stringent homogeneity requirements.

Only is certain cases have segregated standards been employed with any degree of success. In such instances, it was necessary to enlarge the electron beam size and to mechanically drive the specimen with respect to the beam. [9] [10]

An extremely promising method which can be utilized to prepare standards of the required homogeneity is to melt and quench alloys so rapidly that insufficient time is avallable for segregation to occur during solidification. Such a method was described by Duwez et al and is known as splat cooling. [11] The reasoning used was that conductive cooling was the only way to obtain the desired result. All other cooling mechanisms were correctly deemed to be too slow. The original technique consisted of transferring a few hundred milligrams of molten metal to a high velocity; the molten droplet was then allowed to strike a suitably placed massive cold plate of copper or silver. Upon impact the metal spread into a thin nonuniform film about one micron thick called a splat. Investigation by transmission electron microscopy and $x$-ray diffraction has shown that the following may occur in splat cooled material: (1) Solubility of phases may increase markedly, (2) Metastable phases may form, (3) Amorphous solid may be obtained, (4) High temperature phases can be retained down to room temperature, (5) Unusual, highly altered microstructures can form. [11] 
It is the purpose of this paper to report upon the development of a modified Duwez method of splat cooling which can be applied directly to the important practical problem of preparing multicomponent electron probe microanalysis standards. The technique allows material which is miscible in the liquid phase to be prepared rapidly and with a satisfactory degree of homogeneity.

\section{Method and Apparatus}

The requirements for a successful adaption of the method of Diwez to the preparation of microprobe standards were that the apparatus be relatively simple and inexpensive so that it could be easily duplicated. Furthermore, enough material had to be produced so that complete characterization both by the microprobe and by conventional analytical techniques could be carried out. It was decided that several cubic centimeters of material would be a satisfactory yield.

While homogeneity of the alloys produced was a prime requisite, a metal film ore micron in thickness was not desired. Such a thin sample would be difficult to prepare properly for microprobe investigation. [4] Furthermore, the electron beam would in all probability pass completely through the film thus rendering the standard useless.

Therefore, the design requirements for the cooling device were not as stringent as those which Duwez used. In particular, the explosive charge used by Duwez to accelerate the molten metal was unnecessary. [u] For effective cooling of several cubic centimeters of alloy, a much larger copper hearth than that used by Dumez was decided upon. In addition, the hearth was to be pre-cooled with liquid nitrogen. Finally, provision was made to rotate the hearth rapidly during the actual quenching operation. The rapid rotation causes the molten metal to spin out into a number of long relatively flat shards of solld. 
The requirement that the apparatus be relatively simple and yet of wide applicability was met by constructing the basic device of glass. The crucible is made of boron nitride (BN), shaped as a cylindrical bucket having a $20 \mathrm{mils}$ diameter hole ir the base. Quartz crucibies were found to be unsatisfactory. The quartz reacted rapidly with many of the molten alloys.

The modified splat cooling apparatus is showr. as Fig. 1. High purity argon is admitted to both the glass column and the plexiglass crucible chamber at the places indicated. Each of the argon iniets is serviced by a separate gas supply and vent.

The plexiglass chamier has inside dimensions of 11 in. $X 11$ in. $x 11$ in. This relatively large size permits the soparate stand containing the motur driven hearth to be placed in any desired location with respect to the crucible base.

The hearth itself has dn inside configuration which is a hemisphere having a radius of $2.5 \mathrm{in}$. The outside dimensions are those of a 6 in. diameter by $3.5 \mathrm{in}$. ligh right cylinder. This design is the latest of several and is not the ultimate; further modificatior.s may be required for specific alloy systems. Hearth configuration should be questioned when the molten alloy does not spin out into long shards but only forms a bead or when the slloy spins completely out of the hearth. Thus, the hearth configuration and its rotational velocity are the most critical factors in obtaining the required splat-ccoled alloys.

Power for the furnace is supplied by standard induction melting devices. Units rated at hoth 5 and $7.5 \mathrm{~kW}$ respectively were tried: the $5 \mathrm{~kW}$ unit proved tc be sufficient. 
An actual melting experiment using the apparatus is straightforward. The weighed components of the desired alloy are placed into the $B N$ crucible. The hearth is positioned beneath the crucible so as to allow the molter. stream to strike the inside hemispherical opening near the top. Thus the centrifugal force acting on the molten material is maximized spreading the liquid over a larger area. This spreading leads to a larger overall heat transfer rate than would otherwise be possible.

The hearth is filled with liquid nitrogen and the system closed. Argon is allowed to purge the system while the liquid nitrogen in the crucible boils off. When almost all of the liquid nitrogen has bolled of $f$, hearth rotation is begun. Simultaneously, the alloy is brought to the molten state by induction heating. After melting, about two minutes are allowed for homogenization of the liquid.

During the heating phase, the argon atmosphere in the entire apparatus is common. After melting occurs, the surface tension of the liquid seals the small hole in the base of the BN crucible. After the homogenization step, the upper argon vent is sealed by means of the stopcock and the pressure of the incoming argon increased rapidly. This sudden large pressure differential forces the molten metal through the hole and into the hearth which is at a temperature of about $77^{\circ} \mathrm{K}$. The argon atmosphere in the plexiglass portion is allowed to remain at the same pressure throughout. The argon pressure in the glass column is reduced as soon as freezing of the melt has been completed.

As was previously indicated, the speed of rotation of the hearth was found to be a critical factor in the quality of the results obtained. If the speed of rotation was too slow, the molten alloy did not spread aut in a thin layer, and the heat transfer rate was not great enough to obtain 
homogeniety. If the rotational velocity was too great, the molten alloy spun completely out of the hearth. For example, with Al-Mg alloys containing $5 \% \mathrm{Al}$ and less, a ratation speed of $125 \mathrm{n} \mathrm{rpm}$.was used. For those containing more than $5 \%$ Al a rotation speed of $20 m$ rpm was required. The surface tension of the molten alloys seemed to increase with increasing Al content, therefore a higher rotation speed was required to obtain proper spreading of these alloys upon striking the hearth.

\section{Results}

Several systems of binary alloys were prepared and examined, Including $\mathrm{Fe}-\mathrm{NI}, \mathrm{Al}-\mathrm{Cu}, \mathrm{Au}-\mathrm{SI}$, and $\mathrm{Al}-\mathrm{Mg}$. The latter two will serve to Illustrate the results obtainable and the advantages and the few disadvantages of standards prepared by means of splat cooling.

A. Gold-Silicon

The gold-silicon binary system is indicated to have virtually no mutual solid solubllity of elther element in the other. Figure (2) shows the constltution diagram as reproduced from Hansen. [13] Under these conditlons, preparation of homogeneous intermediate Au-Si standards by the conventional process of chill casting followed by a homogenization anneal is not possible. Such a system represents a stringent test of the splat cooling technlque. Accordingly, alloys nominally containing three and six weight percent of sllicon in gold were weighed out using U. S. mint gold and high purity silicon. The latter alloy is at the eutectic composition.

On striking the hearth, these alloys spun out into a number of shards of varying length and cross-section. Several of the shards containing $6 \% \mathrm{Sl}$ were selected for investigation by $x$-ray diffraction. Examination of a typical shard in a precession camera using Mo radlation yielded the pattern shown in FIg. (3). The highly broadened Ilines indicate a very small crystallite size; no attempt to deduce the actual slze was made.

Shards examined in a Debye Scherrer camera using monochromated $\mathrm{Cu}-\mathrm{K}_{a}$ radiation showed structural vapiation. A few showed only a few very broad halos indicating them to be nearly amorphous while others contained some very broad lines and a few contained a great many relatively narrow lines. 
Patterns from four typical shards are shown in Fig (4). No attempt was made to index the patterns but the number of lines present in Fig (4a) indicates the probab!e presence of metastable phases produced by the rapid cooling

Shards for which diffraction patterns were avallable were chosen for electron probe microanalysis. They were mounted in a cold setting resin which was allowed to harden overnight. Mechanical pollshing was carried out on well lubricated papers and wheels in order to minimize sample heating. Final polishing was accomplished using 0.25 micron diamond on selvyt.

The shards were introduced into the microprobe instrument after a bridge of silver based paint was used to assure each a path to ground for the incident electron beam. Coating with carbon falled to accomplish this purpose. The lines chosen were $A u-M_{\beta}$ using an ADP crystal and Si-Ka using an EDDT crystal. The probe voltage was $10 \mathrm{kV}$ with a monitor current of one microamphere. The x-ray emergence angle was $52.5^{\circ}$.

Samples whose structure corresponded to that of Fig. 4 a showed a great amount of random Inhomogeneity; Si count rates varied by as much as 50 percent on randomly chosen points. When the structure corresponded to that of Fig. 4d, the results were somewhat better. Table 1 presents results for such a shard. While the results do not indicate that complete homogeneity was achieved, the coefficient of variation for both gold and silicon is sufficlently low that the shard in question could be used as a standard. In fact, for silicon at the six percent level, the variability approximates closely that reported by the Washington Electron Probe Users Group for analys is of relatively low concentrations in systems where homogeneity had been achieved [2]. Furthermore, it is asserted that certainly no greater confidence than six percent of the amount present for Si in $\mathrm{Au}$ at the six percent level can be expected with present day electron probe correction procedures.

At the three percent si level, instrumental conditions were slightly different in that $A u-L_{a}$ was the line used for analysis with $L$ if as the monochromator. The probe voltage was $20 \mathrm{kV}$; all other conditions were the same. Three shards were examined; the results are shown in Table II. 
Again, complete homogeneity was not achieved but the coefficient of variation is definitely low enough that any of the three shards would be a useful standard.

It is known that splat-cooled material may undergo aging; i.e., post cooling segregation may occur. Splat cooled alloys have been reported to suffer such aging. [13] Cells of rejected $A u$ and $S 1$ result; this destroys the usefulness of the sample for an electron probe microanalyzer standard. Aging occurred in the alloys described in about a week.

Figure (5) shows an electron micrograph of month-old $6 \mathrm{w} / \mathrm{o} \mathrm{Si-Au} \mathrm{illustrating}$ the rejection products.

The possibility of aging suggests that the following procedure should be adopted when using splat-cooled standards:

(1) Obtain x-ray diffraction patterns of the shards immediately after splat-cooling.

(2) Mount the shards giving the broadest diffraction lines in the cold mount having the fastest curing time and lowest curing temperature.

(3) Pollsh - the technlque leading to the least amount of heating of the sample is preferred.

(4) Check for homogeneity in the microprobe.

(5) If satisfactory, obtain the deslred analysis relative intensity data immediately.

(6) Then have the actual sample used analyzed by conventlonal analytical techniques.

B. Alumi num-Magnes I um

The Al-Mg system is Interesting for several reasons. First, there are a great many $\mathrm{Al}-\mathrm{Mg}$ based commerclal alloys. Next, this system permits the most important single microprobe correction procedure, the absorption correction, to be isolated and studied directly. Finally, the constitution diagram presented by Hansen (Fig. 6) shows the system to be moderately 
complex with at least one major area of disagreement: Sultable microprobe standards would offer Investigators the possibillty of a more accurate redetermination of the range 35 to 68 welght percent $\mathrm{Mg} \mathrm{in} \mathrm{Al}$. Accordingly, seven alloy compositions were prepared ranging from five to ninety welght percent of $\mathrm{Mg}$. Diffraction patterns showed substantlally the same type of structurefor all shards chosen. Two such patterns are shown In Fig. (7). The broad, spotty lines indlcate small crystallites some of which may extend through the very thin shard.

Since the diffraction patterns in this case showed only small differences, shards were randomly chosen for microprobe analysis. Four shards of each alloy were checked for homogenelty for both $\mathrm{Al}$ and $\mathrm{Mg}$ using an ADP crystal at probe voltages of 10,15 , and $20 \mathrm{kV}$ respectively. At least five random points were examined on each shard. Shard lengths were typlcally 0.5 to 2 millimeters whlle shard widths were $100 \mathrm{mlcrons}$ or less.

Virtually all counts for all points in every shard were within $3 \sqrt{N}$ of the average count, $N$, for the shard. The value of $N$ was set to range from 100,000 to 200,000 depending on the sample. The agreement of $\mathbf{N}$ for different shards of the same nominal composition was well within one percent relative. Thus, each alloy prepared was found to be homogeneous to a one-micron probe and each shard was found to be of the same composition as other shards from the same melt. Therefore, each of the required homogenelty characterlstics for standards for electron probe microanalysis was fully satisfied.

Some time (approximately one week) after checking for homogeneity, the intensity data from the shards was taken relative to that of pure $\mathrm{Mg}$ and pure $A l$ as well as background intensitles. Background for Al was 
measured on peak with a Mg sample while background for Mg was measured on peak with an $\mathrm{Al}$ sample. Line to background ratios for $\mathrm{Mg}$ and $\mathrm{Al}$ were greater than 250 to 1 . Instrumental stability was monitored by count Ing on the pure elements after each shard was Investlgated; all such counts were within $3 \sqrt{\mathrm{N}}$ counting error.

Since all shards from the same melt gave the same count rate within the counting error, a single $1 / 1_{0} \equiv k$ value could be obtained for each composition. In considering the corrections to be applied, atomic number effects could be ruled out since $\mathrm{Al}$ and $\mathrm{Mg}$ are adjacent in the periodic table.

The Mg-K $K_{\alpha}$ lines will be exclted by the Al-K $K_{\alpha}$ since the Mg-K absorption edge lies at a lower energy than the Al-Ko energy. Therefore, a fluorescence correction is required for $\mathrm{Mg}$ as well as an absorption correction. The magnitude of the correction to be applied is small since the absorption coefficients of both $\mathrm{Al}$ and $\mathrm{Mg}$ for $\mathrm{Mg}-\mathrm{K} \alpha$ are nearly equal and since the absolute K-fluorescence yield from Al is very small. [14] The PhillbertDuncumb relation was used to correct for absorption effects whlle Castaing's relation was used to corract for fluorescence. L1] [15] The total correction calculated at all Mg compositions is one percent relative or less. Therefore, Mg in $\mathrm{Al}-\mathrm{Mg}$ represents very nearly the Ideal case in which the measured relative $x-$ ray fluxes correspond to the actual concentrations across the entire range of compositions.

For $A 1$, there wlll be no extraneous $x$-ray excltation. However, a large absorption correction is to be expected because the mass attenuation coefficient, $(\mu / \rho)$, of $\mathrm{Mg}$ for $\mathrm{Al}-\mathrm{K}_{\alpha}$ is more than an order of magnltude greater than the $(\mu / \rho)$ of Al for Al-K. [16] In this case, the large absorption correction for Al in Al-Mg can be isolated for experimental investigation. 
In an evaluation of absorption correction procedures, it was found that the Phllibert-Duncumb method gave satisfactory results In most cases. [17] Therefore, this method was adopted for the $\mathrm{Al}$ in $\mathrm{Al}-\mathrm{Mg}$ data.

As a final check, quantltative chemical analysis was performed on four of the seven alloys. An insufficient quantity of material was avallable In two cases and in the remaining instance, contamination of the specimen submitted caused poor results. The source of this contamination could not be traced. The analyses are clalmed to be accurate to within an error of $0.5 \%$ relative.

In order to arrive at the true compositions for the three remaining alloys, the Ziebold-ogilvie method was used. The four analyzed alloys were used to obtain the "a" value for the system at each operating voltage by means of the relation: [18]

(1) $a=\left(\frac{c}{k}\right)\left(\frac{1-k}{1-c}\right)$

From the four values so computed, an average value, $\bar{a}$, was calculated for a given operating voltage. Then using this empirical $\bar{a}$, the compositions were obtained for the remalning alloys by means of Eqn. (2):

$$
\text { (2) } 6=\frac{\bar{k} \bar{a}}{k(\bar{a}-1)+1}
$$

The values for $C$ computed at the three operating voltages were nearly equal. As a check of the validity of the average a value, the known compositions were recomputed. Deviations were less than the experimental error for the determination of $k$. Therefore, the compositions calculated by this means are considered to be entirely valid. The true composition versus " $k$ " curves are shown plotted in Flg. 8.

Final analytical data for both $\mathrm{Al}$ and $\mathrm{Mg}$ are shown in Table III. In the cases indicated, it was not possible to obtain microprobe data due to speclmen 
Instability, e.g., aging prior to measurement of relative intensity data. This again points out that splat cooled standards should be used as soon after preparation as possible.

Table III shows for Mg analysis, that the accuracy errors range from zero to 4.4 percent of the amount present and that for fourteen results, six errors are negative, seven positive, while one is zero. The root mean square deviation from the true composition is less than $1.7 \%$ over the composition range 10 to 75 percent $\mathrm{Mg}$. This variation is representative of how accurately the relative intensity data, $k$, were taken in each case since the correction curve for $\mathrm{Mg}$ in $\mathrm{Al}-\mathrm{Mg}$ is essentially linear. The fact that no systematic deviation was noted reenforces this viewpoint.

However, as expected $[17]$, in the case of $\mathrm{Al}$ in $\mathrm{Al}-\mathrm{Mg}$, systematic errors are clearly indicated by the results in Table 111 . Some ninteen of twenty errors are positive and the remaining error is nearly zero. Furthermore, at lower Al concentrations, the devlation from the true value is greater than ten percent. In the middle of the range, the deviation is about three percent 0 while at high Al concentrations, the deviation is one percent or less. The magnitude of the absorption correction Increases markedly with increasing Mg content. Thus, the systematic error increase as a function of the amount of Mg present signifles an increasing error in the applied absorption correction. However, it is worth noting that the Philibert-Duncumb model yields calculated Al compositions which are nearly equal for the three operating voltages used. The data seem to indicate that the errors observed were caused by an uncertainty in the $x$-ray mass attenuation coefficient of $M g$ for Al-K $K_{\alpha}$ radiation; the published value appears to be too great. 
The Mg results clearly show that the Al-Mg alloys prepared by the splat coolling technique stalsfy all of the requirements for a standard suitable for electron probe microanalysis. The Al results clearly show tha need for standards in the numerous cases where vital correction model input parameters such as $(\mu / \rho)$ data are in doubt.

\section{Summary and Conclusions}

The splat cooling device described is capable of preparing satisfactory standards for electron probe microanalysis. A crucible which does not react with the molten alloy is required. The liquid alloy must be misclble as well. Finally, some experimentation with hearth design and rotational velocity is usually required. The apparatus is relatively simple and inexpensive. Therefore, it may be dupllicated in most laboratories wl thout excessive difficulty. The value of the capability for preparing specifically required standards virtually at wlll is readily appreclated.

The yield is several cublc centimeters of solid which is usually sufficlent for both electron probe microanalysis and conventlonal chemical analysis. It is imperative that the standards be carefully characterized wi th regard to homogeneity within shards and from shard to shard ty means of the $\mathrm{mlcroprobe.} \mathrm{The} \mathrm{required} \mathrm{analysis} \mathrm{data} \mathrm{should} \mathrm{be} \mathrm{obtained} \mathrm{as} \mathrm{soon} \mathrm{after}$ preparation of the standards as possible in order to minimize possible difficulties due to aging.

The results for Al-Mg alloys show that chemical analysis is definitely required. The actual compositions obtained often differ greatly from the compositions predicted by weighing alone. This is not considered to be a serious drawback since it is only necessary to establish a " $k$ " versus true concentration curve. 
It is concluded that the splat cooling technique when properly carried out will permit the investigator to prepare standards homogeneous to the extent that the maximum analysis error will be equivalent to the error in measuring relative $x-$ ray intensities, $( \pm 3 \sqrt{N})$. it can be foreseen that with standards available, results from quantitative electron probe analysis will be comparable to those obtained by $x$-ray spectrochemical analysis.

\section{Acknowledgments}

The authors wish to thank Mr.C.J.Bechtoldt (NBS) for the $x-r a y$. diffraction data, Mr.R.E. Michaelis and the Analytical Chemistry Division (NBS) for the analysis of the Al-Mg samples, Mr.D.B.Ballard (NBS) for the electron microscopy, Mr.D.L.Vieth (NBS) for aid in preparing samples for microprobe examination, Mr.Paul Soules (Melpar-NASA) for general technical assistance, and He.K. F. J. Heinrich (NisS) for helpful discussion. 


\section{References}

I R. CASTAING, Application of Electron Probes to Local Chemical and Crystallographic Analysis, Thesis, University of Parls, (1951).

2. L. S. BIRKS, J.V.GILFRICH, and H. YAKOWITZ, Report of the Washington Electron Probe Users Group, ASTM Spec. Tech. Publ. - In press。

3 J.V. SMITH, "Production of $x$-rays", Notes of a course taught at California Institute of Technology, Pasadena, Calif. 39PP (1965).

4 H. YAKOWITZ, Evaluation of Specimen Preparation and the Use of Standards in Electron Probe Microanalysis, ASTM Spec. Tech. Publ. - In press.

5 H. YAKOWITZ, D. L. VIETH, K. F. J. HEINRICH and R. E. MICHAELIS, Homogeneity Characterization of NBS Spectrometric Standards II: Cartridge Brass and Low-Alloy Steel, Adv.X-ray Anal. 2289 (1966).

6 J. I. GOLDSTEIN, R. E. HANNEMAN and R. E. OGILVIE, Diffusion in the Fe-Ni System at 1 Atmosphere and $40 \mathrm{k}$ Bar Pressure, Trans. AIME 233, $812(1965)$.

7 T. 0. ZIEBOLD, Ternary Diffusion in Cu-Ag-Au Alloys, PhD Thes is (MIT) $150 \mathrm{pp}(1965)$.

8 H. YAKOWITZ, D. L. VIETH, and R. E. MICHAELIS, Homogeneity Characterization of NBS Spectrometric Standards III: White Cast Iron and Stainless Steel Powder Compact, NBS Misc. Publ. 260-12 - In press.

9 L. S. WALTER, "A Convenient Method for the Preparation of Silicate Standards for Microprobe Analys/s", Optique des Rayons X et Microanalyse, R. Castaing, P. Deschamps, J. Philibert, Eds., Ed Sci. Hermann (Paris) 1966 - In press.

10 S. H. MOLL, "Practical Methods for Experimentally Calibrated Concentration Determinations with the Electron Beam Microanalyzer," Proceedings International Conference of Electron and Ion Beam Science in Technology, R. Bakish, Ed。, lst Ed. (1964), p. 825 . 


\section{References - (cont.)}

11 P.DUWEZ, R. H. WILLENS, and W. KLEMENT, JR., Continuous Series of Metastable Solid Solutions in Ag-Cu Alloys, J. Appl. Phys. 31, 1136 (1960).

12 M. HANSEN, Constitution of Binary Alloys, Second Ed., McGraw-Hill, New York (1958), P. 105 cf and P. 232.

13 W. KLEMENT, JR., Lattice Parameters of the Metastable Close Packed Structure: in Aq-Ge Alloys, J. Inst. Metals 90, 2.7 (1961).

$1 \%$ J. LABERRIGUE -FROLOW and P. RADVANYI, Le Rendement de Fluorescence de la Couche K, Mesures Spectrométr iques sur $\begin{aligned} & 99 \\ & 43\end{aligned}$ Tc* $(6.04 \mathrm{~h})$ et $\begin{array}{r}115 \\ 49\end{array}$ In* $(4.5 \mathrm{~h})$, J. Phys. Radium 17, 944 (1956).

15 P. DUNCUMB and P. K. SHIELDS, "Effect of Critical Excltation Potential on the Absorption Correction", The Electron Microprobe, T. D. McKinley, K. F. J. Heinrich, and D. B. Wittry, Eds., J. Wiley, New York (1966) P. 284.

16 K. F. J. HEINRICH, "X-ray Absorption Uncertainty", The Electron Microprobe, T. D. McKinley, K. F. J. Heinrich and D. B. Wittry, Eds., J. Wiley, New York (1966) p. 296.

17 K. F. J. HEINRICH and H. YAKOWITZ, Quantitative Electron Probe Microanalysis: Absorption Correction Uncertainty, Presented at First National Conference on Electron Prove Mlcroanalysis, College Park, Maryland, May 4-6, 1966.

18 T. 0. ZIEBOLD and R. E. OGILVIE, An Emperical Method for Electron Microanalysis, Anal. Chem. 36,322 (1964). 


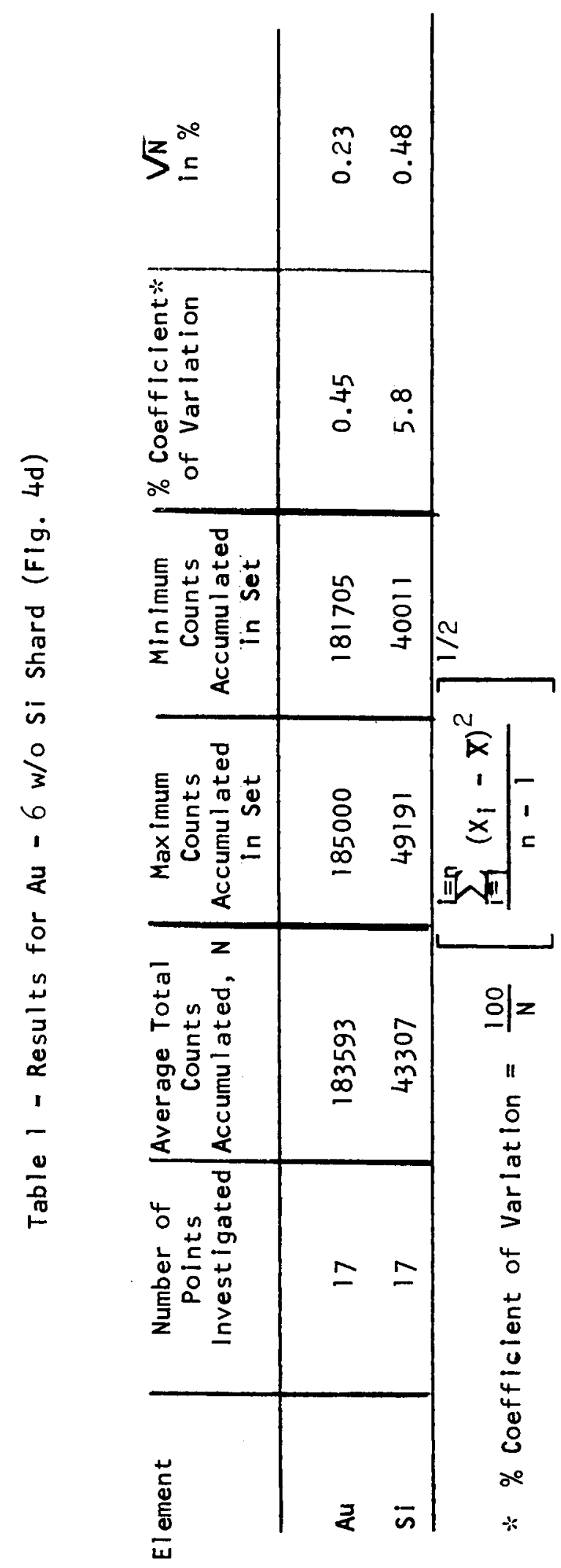




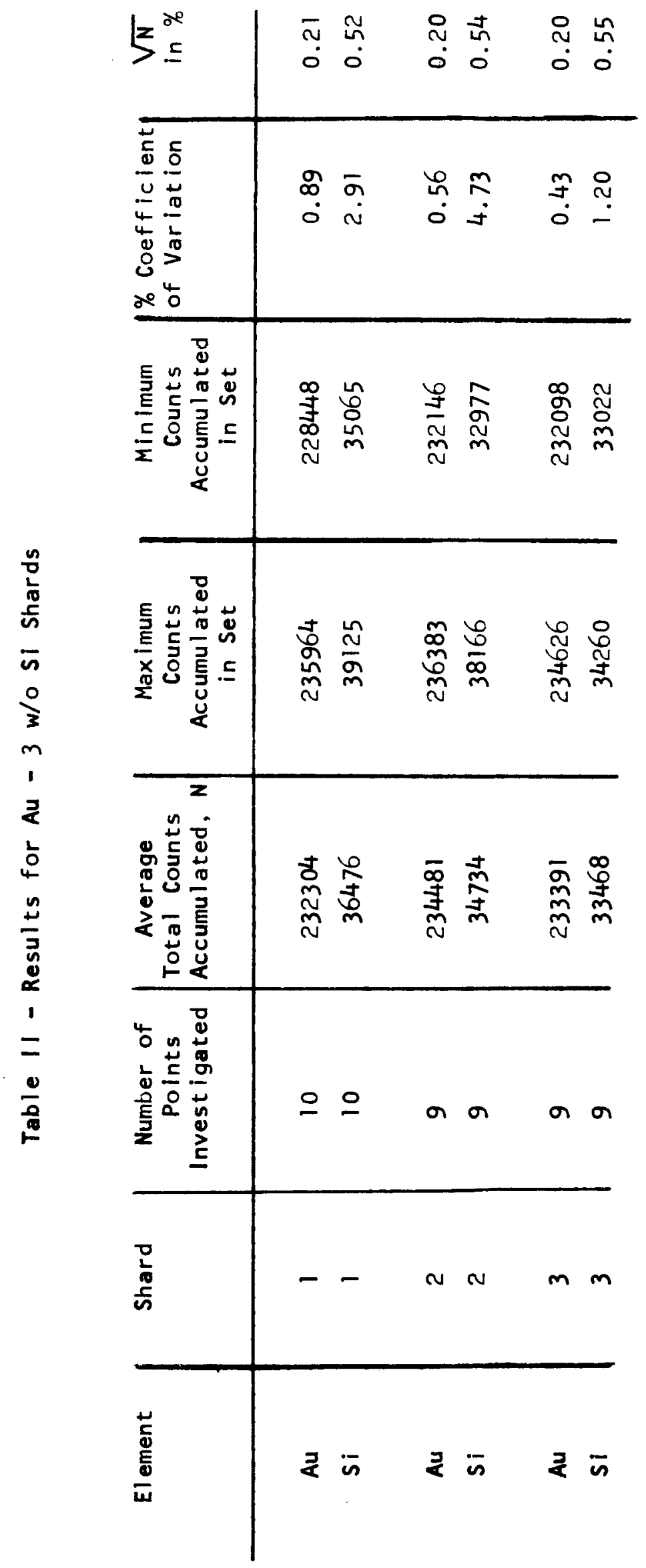




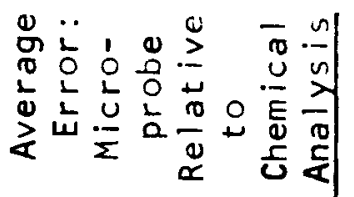

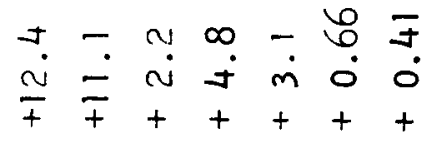

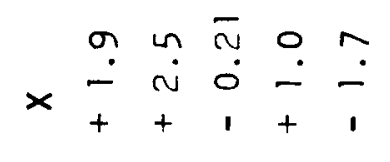

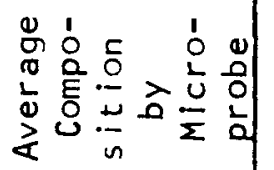

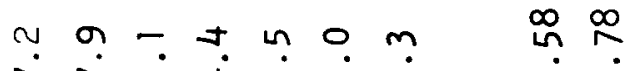

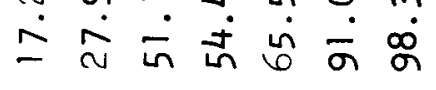

- $\dot{r} \stackrel{\infty}{m} \dot{0} \dot{n}$

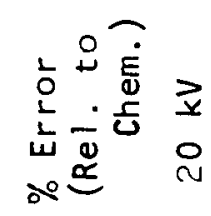

0 - 의

离

$\dot{m}=\dot{0} \dot{m}-\dot{0} \dot{0}$

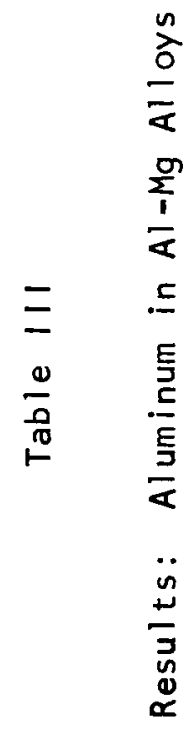

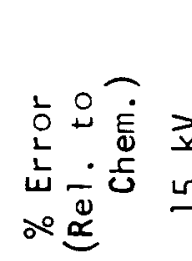

$4 \div \dot{0} \div-\dot{0}$

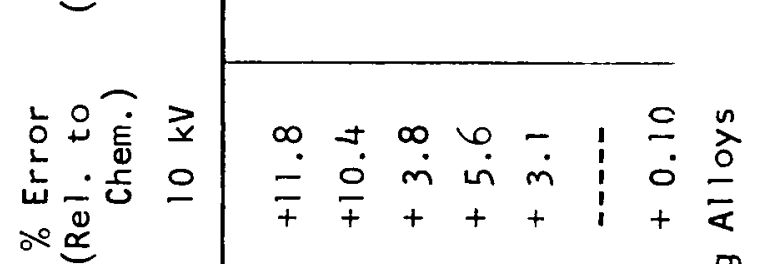

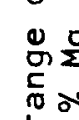

$\stackrel{N}{n}$

$\frac{0}{2}$

- ᄂ

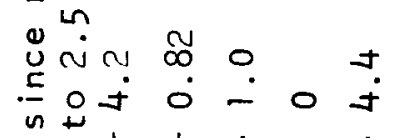

总

$-$

呈.

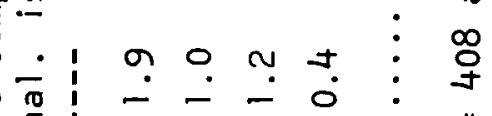

$\frac{\pi}{\frac{u}{4}} \cdot$

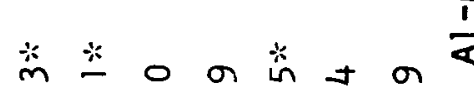

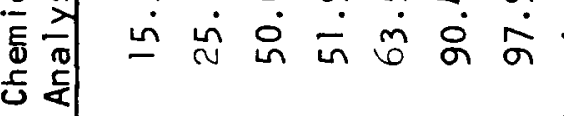

Ho n -0 a $a \frac{a}{a}$

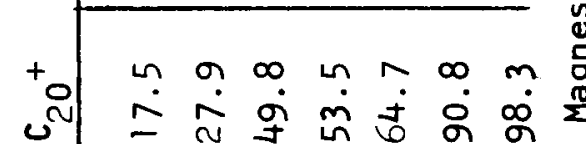

出 $\ln \infty \quad \infty \quad \infty \quad \infty$ in

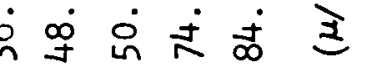

$+$

- 0

5

$+$

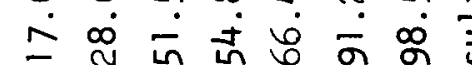

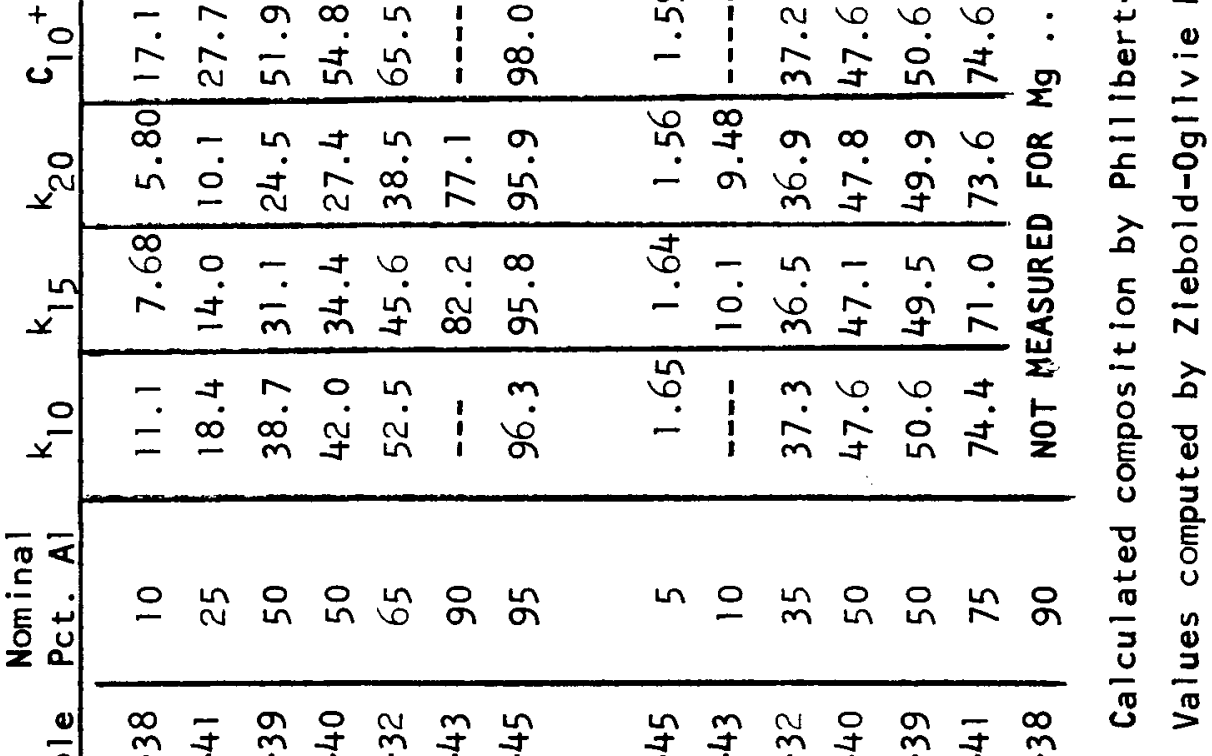

- 0 क क ज

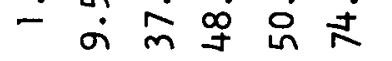

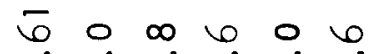

a

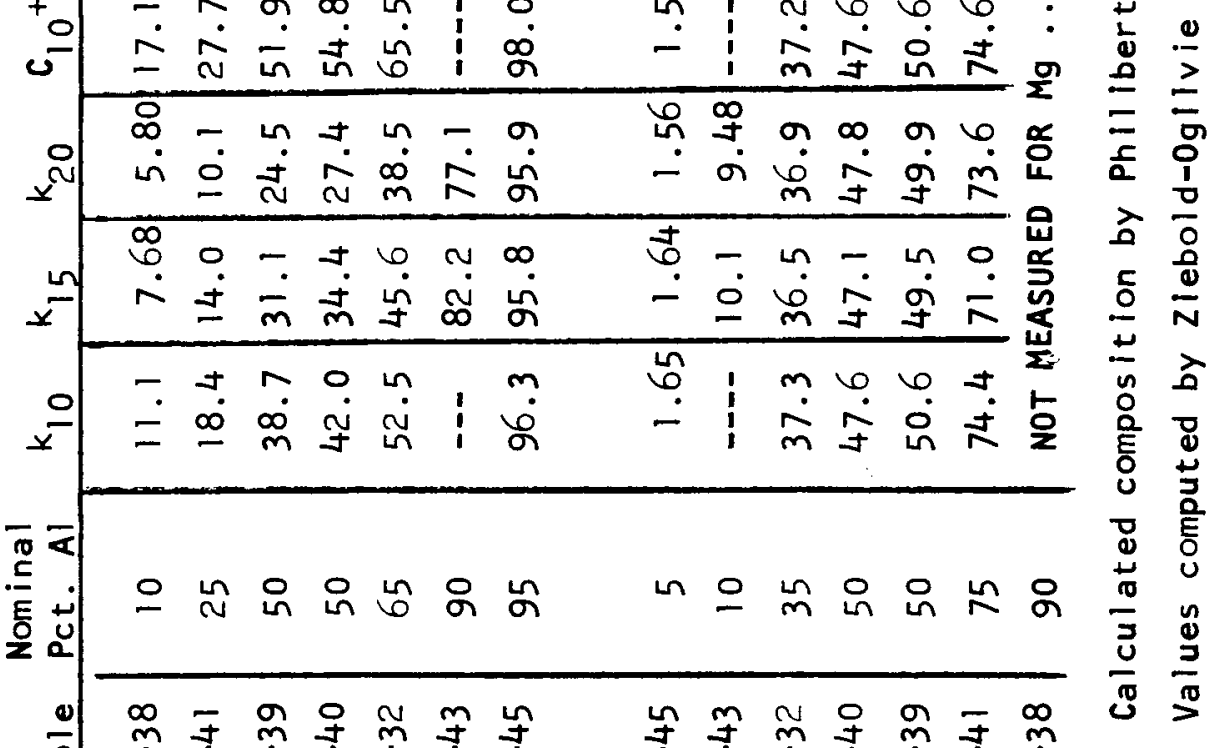

กำ

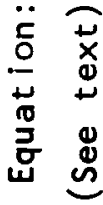

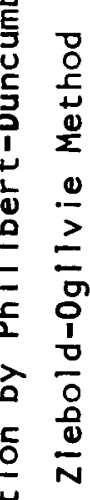

\%

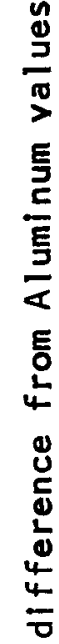

วิ

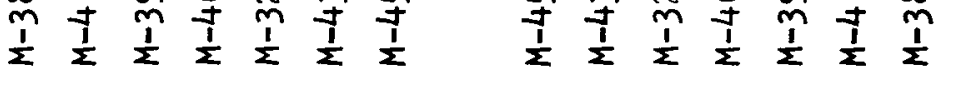




\section{Figure Captions}

Figure Number

\section{Caption}

Modified splat cooling apparatus

Constitution diagram for Au-Si (after Hansen)

Precession camera diffraction pattern of Au-6 w/o Si using

Mo radiation

Debye-Scherrer photographs of Au-6 w/o shards

Shard showing probable presence of metastable phases

Shard (2) showing probable presence of metastable phases

Shard (3) showing only a few broad lines

Shard (4) showing nearly amorphous (glass-like) pattern

Election micrograph of month-old Au-6 w/o Si showing dendritic formations amld former featureless structure $\times 13500$

Constltution diagram for Al-Mg (after Hansen)

Debye-Scherrer patterns from typical Al-Mg shards (Sample M-32)

True weight percent versus measured relative $x$-ray intensities for $\mathrm{Al}$ in $\mathrm{Al}-\mathrm{Mg}$ at 10,15 , and $20 \mathrm{kV}$ operating voltages. 


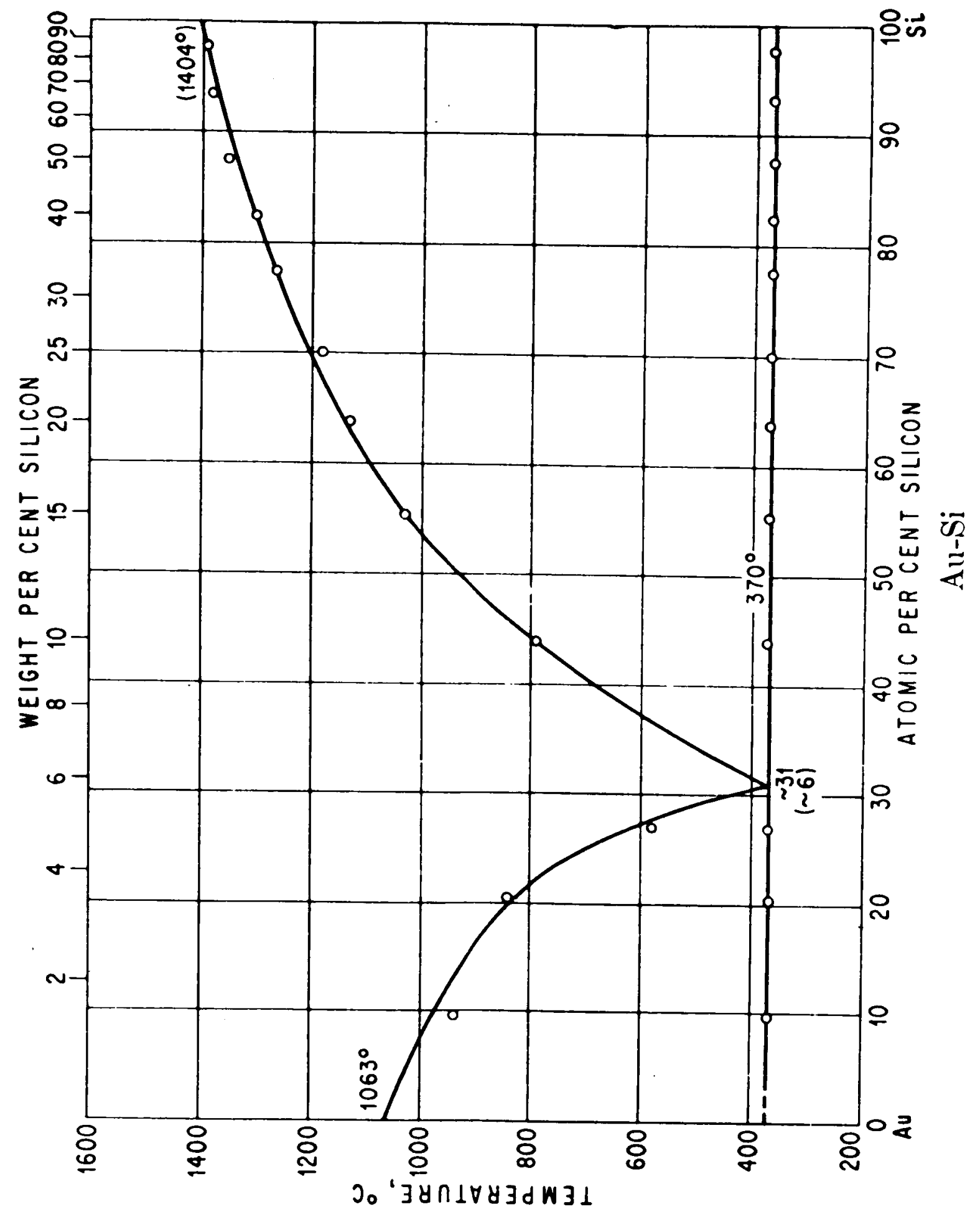




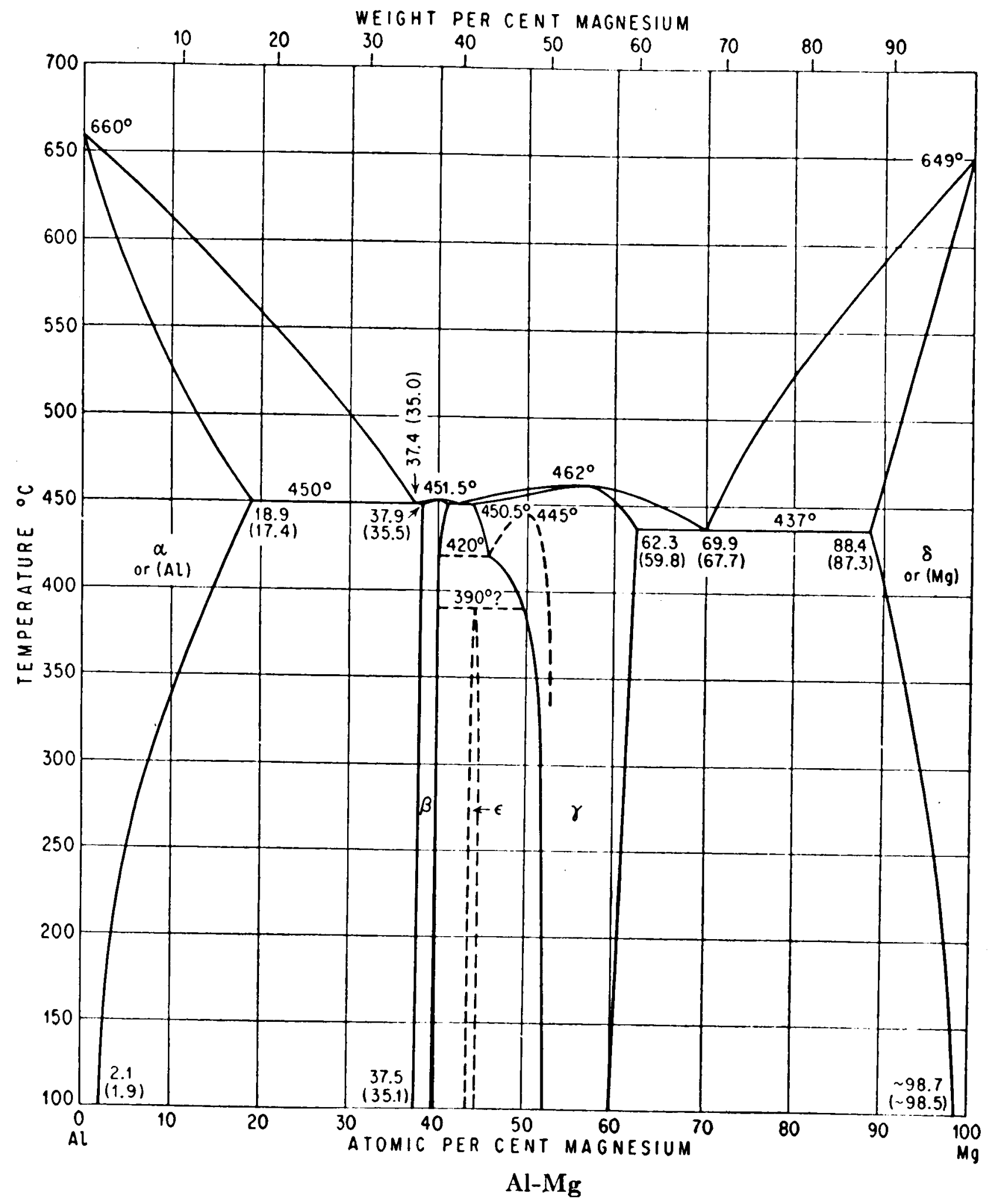




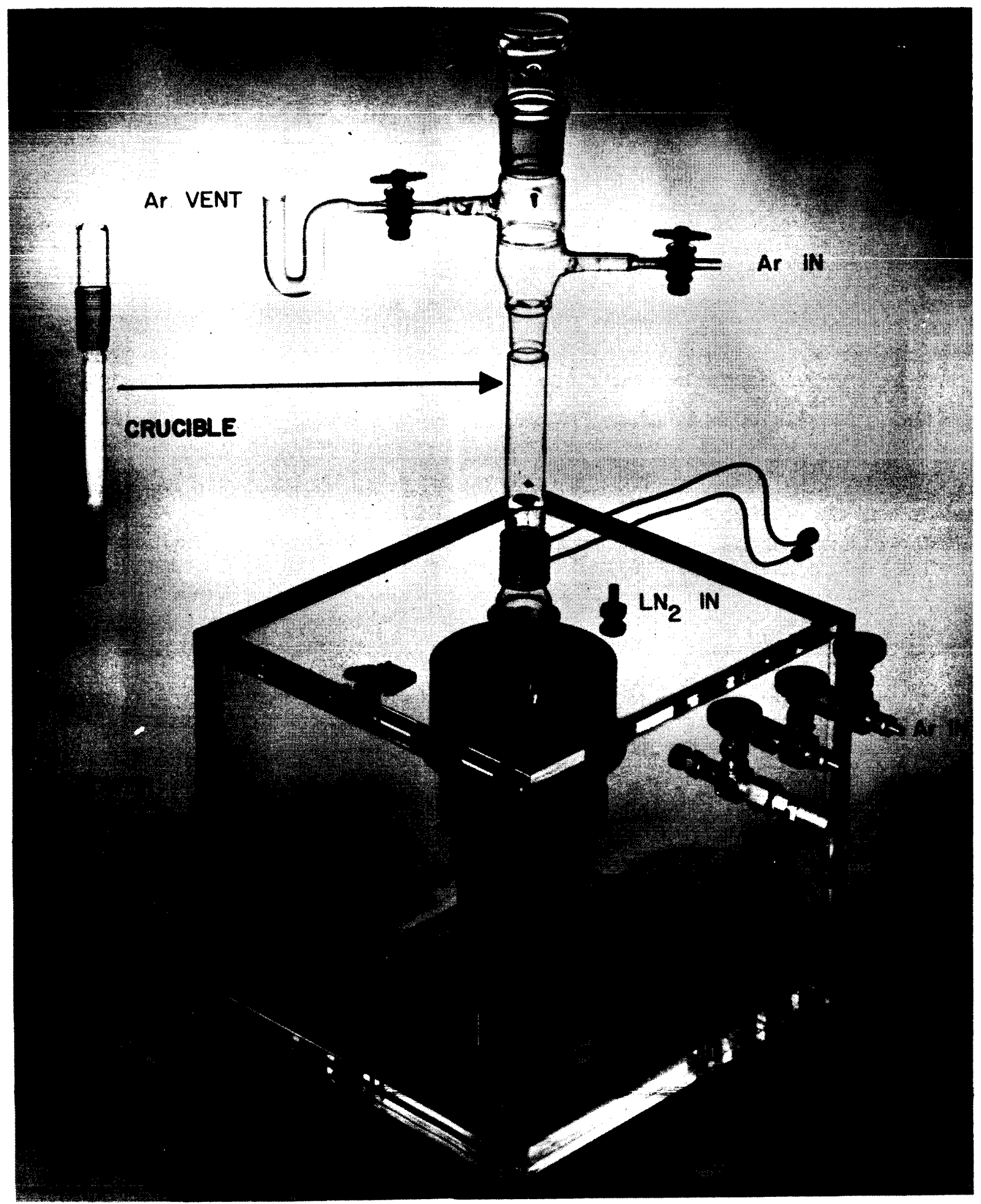




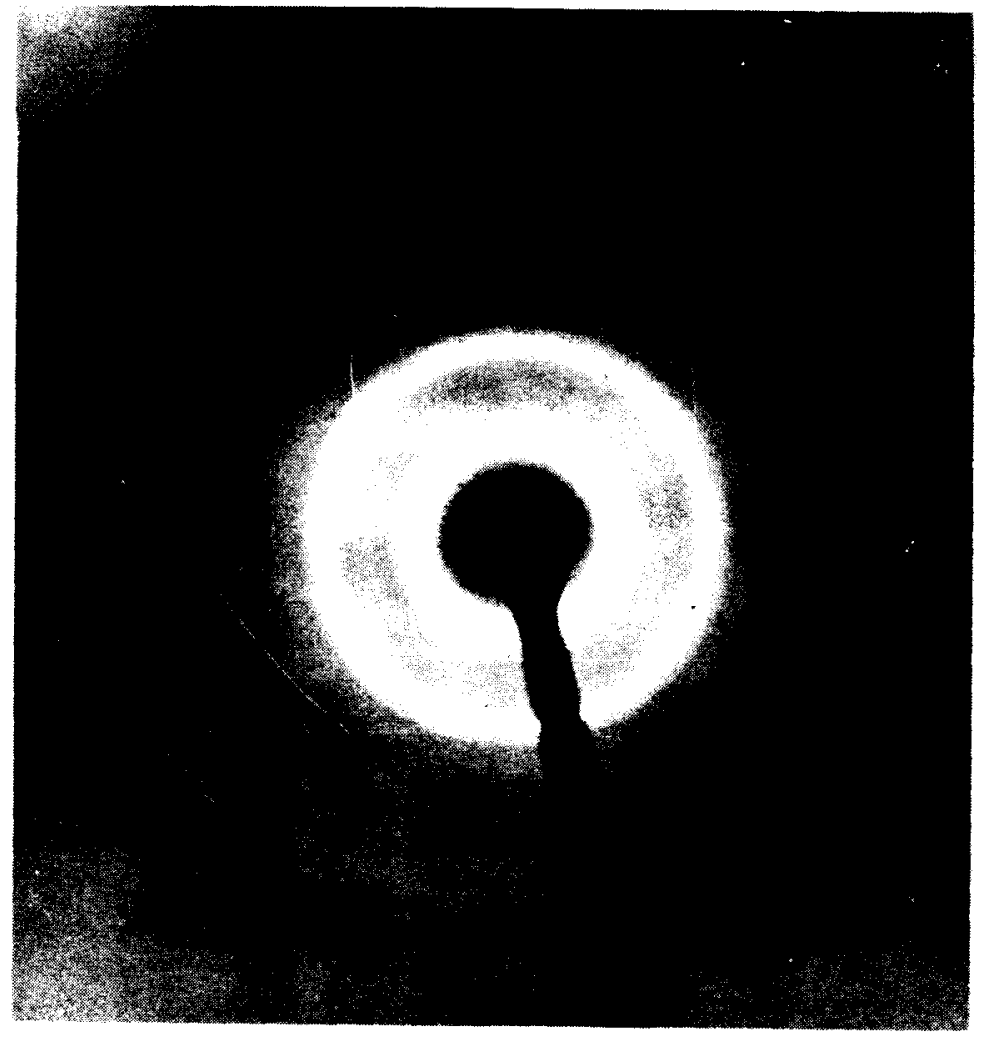



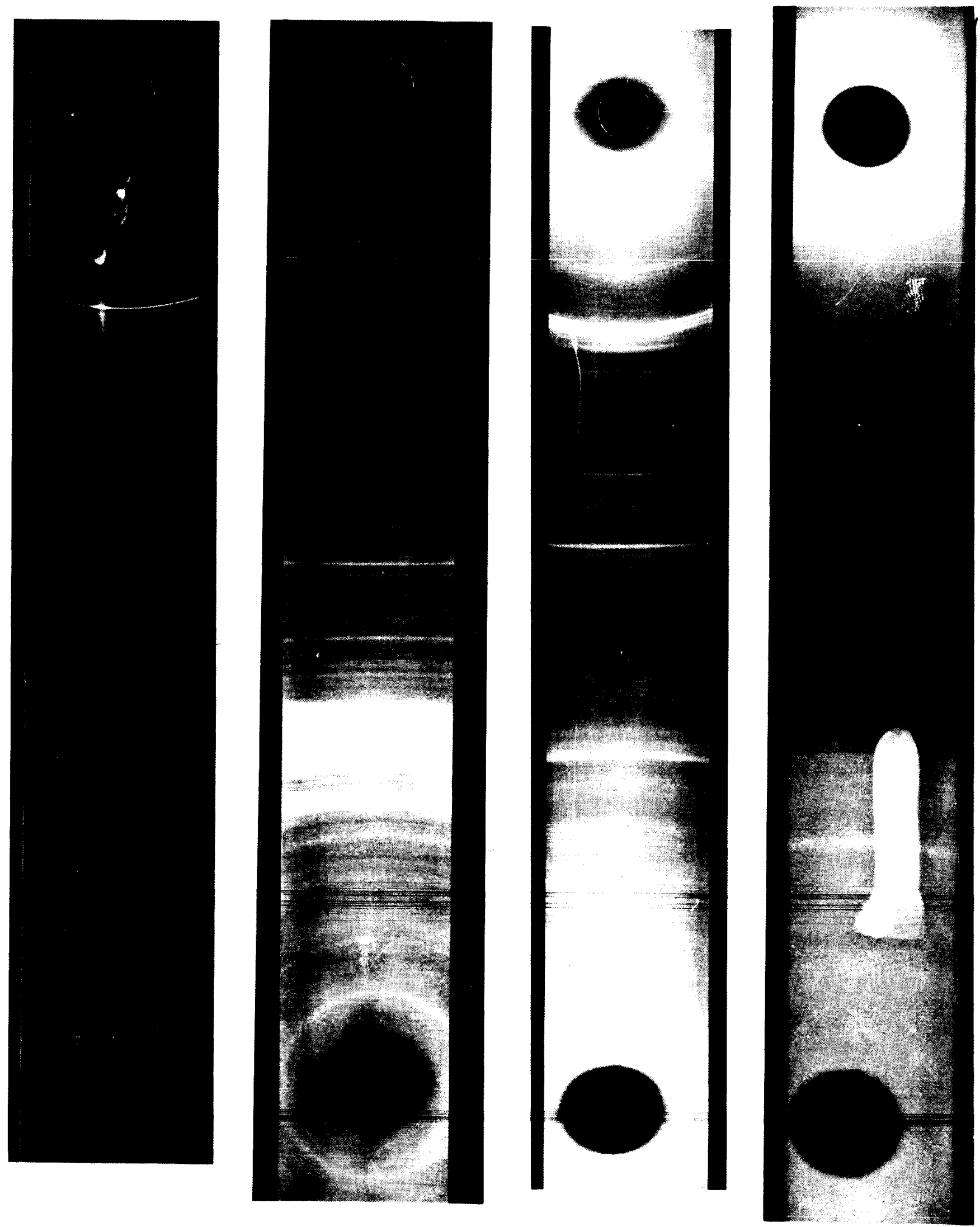


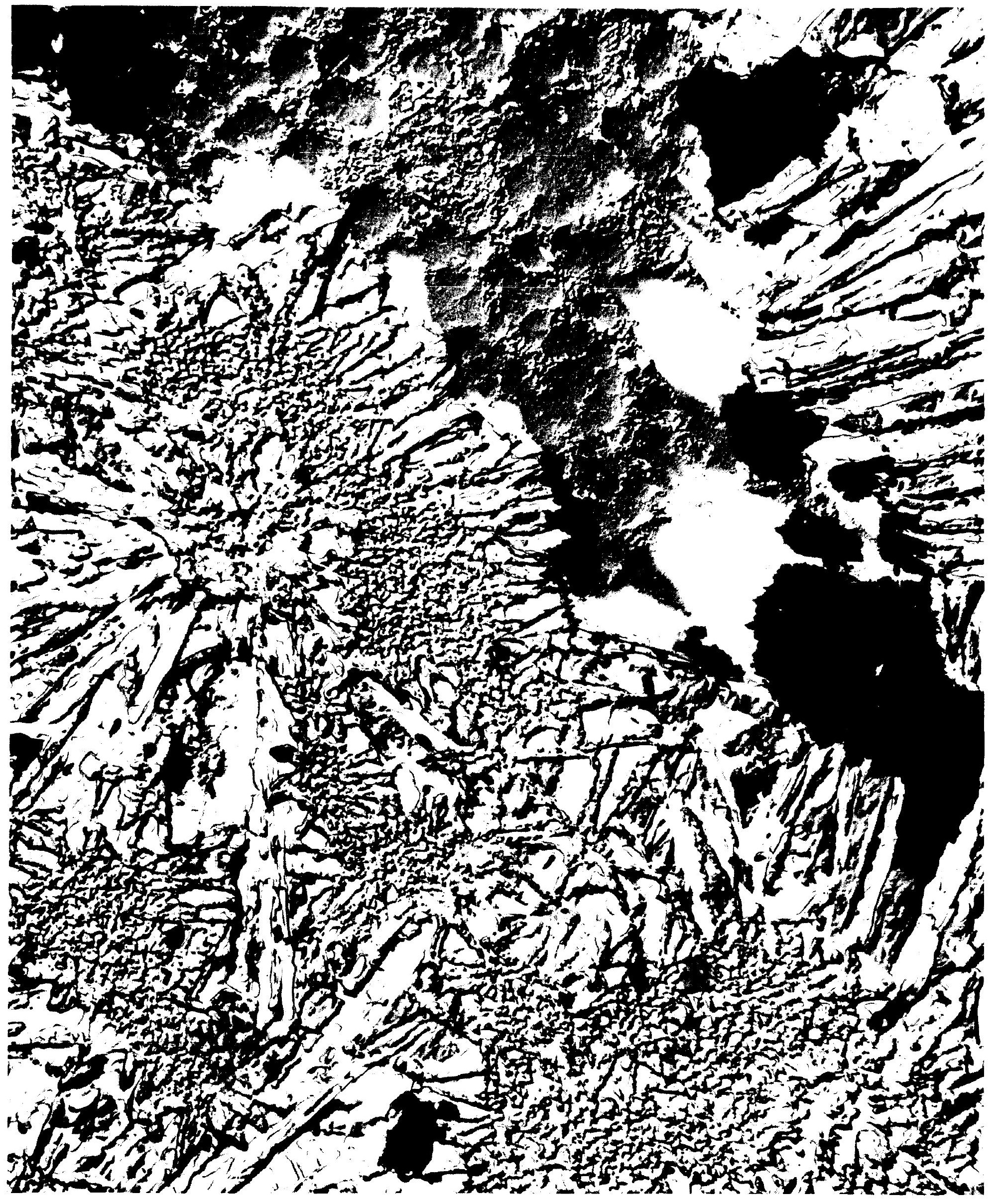



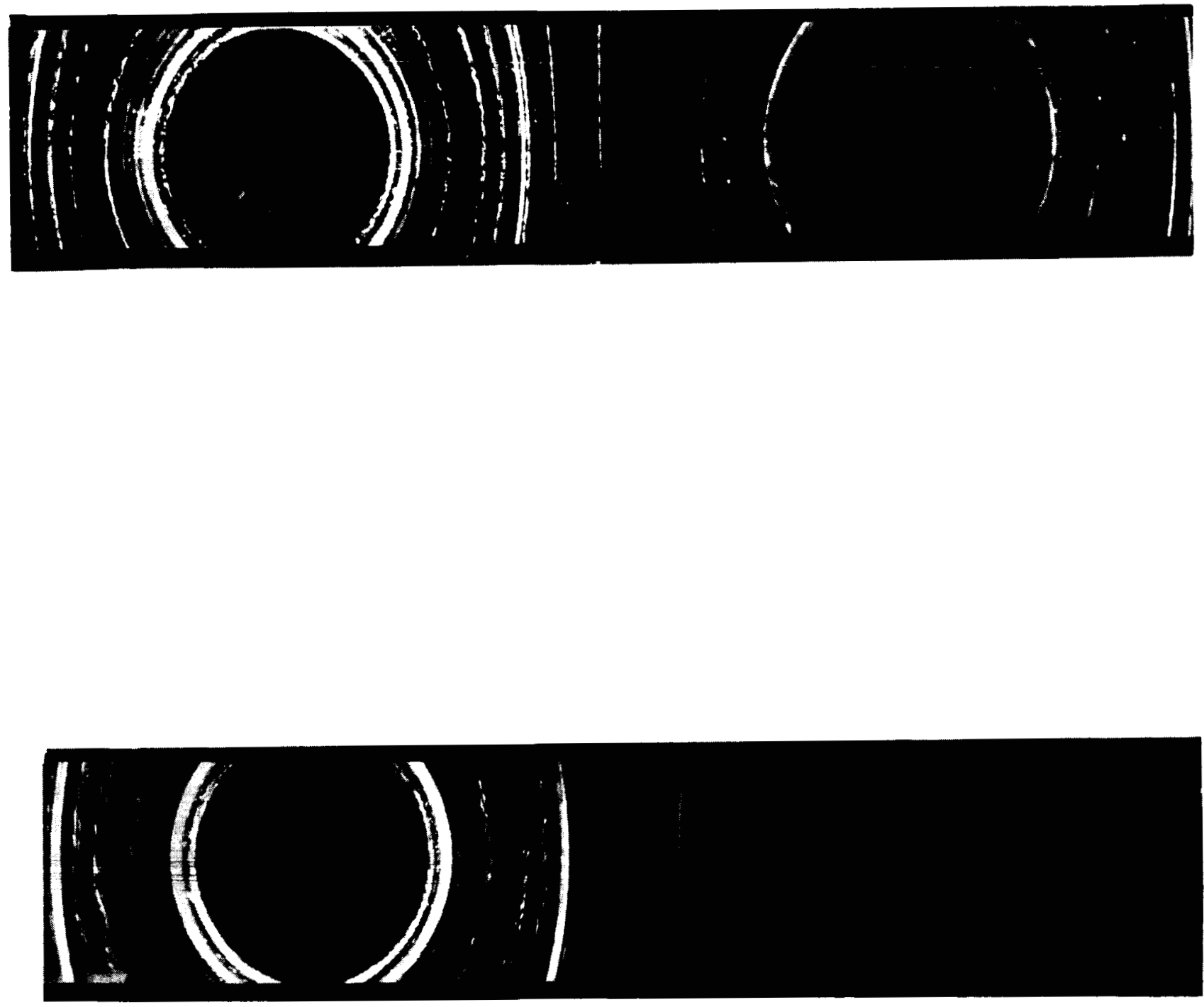
Measured Relative X-Ray Intensity: k

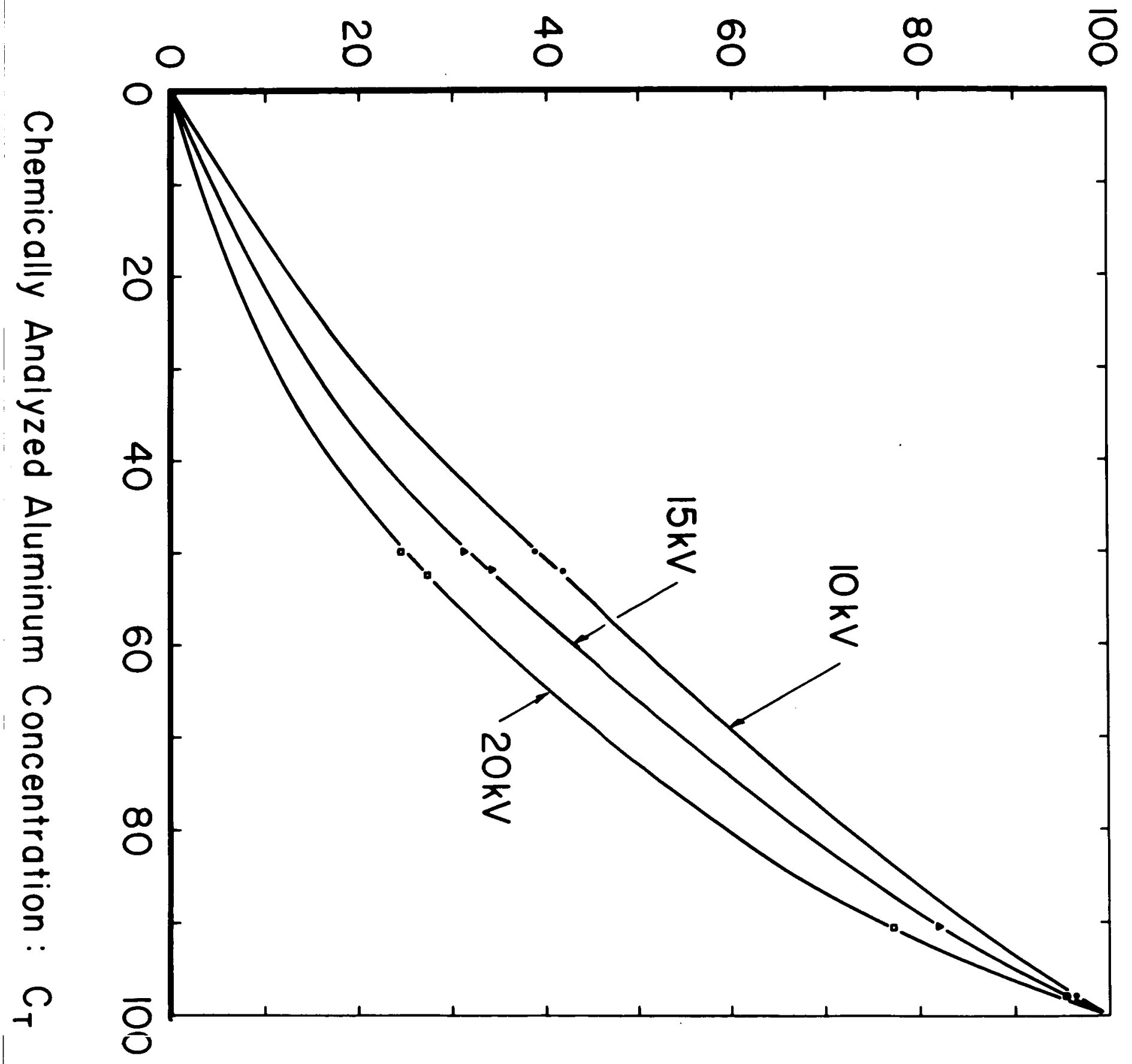

